\title{
Intensitas Penyakit Busuk Pangkal Batang Pada Tanaman Lada (Piper nigrum L)Di Desa Batuah Kecamatan Loa Janan Kabupaten Kutai Kartanegara.
}

\section{The Intensity Of Stem Root Rot Disease In Pepper Plants (Piper Nigrum L) In Batuah Village, Loa Janan Subdistrict, Kutai Kartanegara Regency.}

\author{
Ni'matuljannah Akhsan ${ }^{* 1)}$, Albert Patangke ${ }^{* 2}$ \\ *)Minat Studi Hama dan Penyakit Tanaman, Program Studi/Jurusan Agroekoteknologi, Fakultas \\ Pertanian, Universitas Mulawarman, Samarinda, Kalimantan Timur, Indonesia. \\ Kontak person: ${ }^{11}$ sempajaku@gmail.com \\ 2)albertpatangke@gmail.com
}

\begin{abstract}
ABSTRAK
Varietas Malonan-1 merupakan tanaman lada yang berasal dari Kalimantan Timur yang sudah menjadi lada unggul nasional. Lada ini mengandung minyak atsiri sekitar 2,35\%, oleoserin $11,23 \%$ dan piperin 3,82\% serta toleransi terhadap penyakit busuk pangkal batang. Hasil survei pendahuluan di desa Batuah Kabupaten Kutai Kartanegara Kalimantan Timur, ditemukan serangan penyakit busuk pangkal batang pada lada Malonan-1, oleh karena itu perlu dilakukan penelitian untuk mengetahui berapa besar intensitas penyakit busuk pangkal batang pada saat ini dan mengidentifikasi jamur penyebab penyakit busuk pangkal batang pada tanaman lada.

Penelitian ini dilaksanakan selama 5 bulan terhitung mulai Januari hingga Mei 2019. Lokasi penelitian di Desa Batuah Kecamatan Loa Janan, Kabupaten Kutai Kartanegara dan di Laboratorium Hama Penyakit Tumbuhan Fakultas Pertanian Universitas Mulawarman. Penelitian meliputi kegiatan di lapangan dan di laboratorium. Kegiatan di lapangan yakni survei langsung di delapan kelompok tani lada dan menghitung intensitas penyakit. Dilakukan juga pengambilan sampel tanaman bergejala penyakit busuk pangkal batang untuk dibawa ke laboratorium. Kegiatan di laboratorium yaitu persiapan alat dan bahan untuk mengisolasi sampel tanaman lada. Koloni jamur hasil isolasi dimurnikan kemudian diidenfikasi dan dilanjutkan dengan postulat Koch.

Rata-rata intensitas penyakit busuk pangkal batang pada tanaman Lada pada saat ini di desa Batuah adalah 14,58\% (ringan), intensitas tertinggi pada kelompok tani Lada Muda 26,52\% dan intensitas terendah pada kelompok Tani Beringin Jaya 4,3\%. Berdasarkan hasil isolasi, penyakit pangkal batang tanaman lada (Piper nigrum L) di Desa Batuah Kecamatan Loa Janan Kabupaten Kutai Kartanegara adalah Phytophthora capsici L.

Kata kunci : Phythophthora capsici, busuk pangkal batang, tanaman lada, Malonan-1.
\end{abstract}

\section{PENDAHULUAN}

Lada (Piper nigrum L) merupakan salah satu tanaman rempah yang mempunyai nilai ekonomi cukup tinggi di Indonesia. Nilai devisa yang dihasilkan dari ekspor lada pada tahun 2016 sebesar US \$ 431,14 juta, dengan total produksi mencapai 82,17 ribu Mg (Kementrian Pertanian RI 2017). Sebagian besar tanaman lada diproduksi oleh petani dalam bentuk perkebunan rakyat yang menyerap banyak tenaga kerja. Usaha tani lada telah menghidupi ribuan petani di Indonesia, khususnya di daerah pengembangan tanaman lada dimana tanaman pangan tidak dapat tumbuh dengan baik. Daerah pengembangan lada yang terkenal dengan lada hitam yang terdapat di daerah Lampung dan lada putih terdapat di daerah Bangka. Pengembangan tanaman lada lainnya terdapat di daerah Kalimantan Barat, Kalimantan Tengah dan Kalimantan Timur, serta Sulawesi
Selatan dan Sulawesi Tenggara (Manohara dkk., 2006).

Peningkatan produksi total tanaman lada di Indonesia tidak begitu signifikan. Salah satu penyebabnya karena gangguan berbagai macam penyakit, khususnya penyakit busuk pangkal batang yang disebabkan oleh cendawan Phytophthora capsici. Penyakit ini sangat ditakuti petani karena dapat menyebar dengan cepat dan mematikan tanaman dalam waktu singkat (Manohara dkk., 2005). Penyakit ini sulit di deteksi pada awal perkembangannya karena mudah terbawa oleh air, tanah atau menyebar dari bagian tanaman yang terserang. Merusak tanaman mulai dari masa pembibitan dan tanaman lada muda sampai tanaman yang telah berbuah. Tanaman yang terserang dapat layu dan mati jika penyakit yang terjadi pada akar atau pangkal batang (Manohara dkk., 2005; Semangun, 2000). 
Gejala penyakit berupa layu, baru muncul setelah sebagian besar akar dan pangkal bantang telah rusak. Layunya tanaman ini disebabkan karena terputusnya suplai air dan unsur hara ke bagian atas tanaman. Perkembangan gejala layu ini bervariasi, ada yang lambat dan ada yang cepat. Gejala layu yang lambat sangat menyulitkan dalam pencegahan secara dini penyebaran dari patogen penyebab penyakit tersebut. Lamanya perkembangan gejala penyakit layu sejak infeksi patogen pada akar sampai munculnya gejala layu belum diketahui secara pasti.

Intensitas serangan penyakit di Kabupaten Kutai Kertanegara tergolong ringan dengan intensitas serangan penyakit yang kurang dari $10 \%$. Data rekapitulasi pengamatan OPT dari Dinas Perkebunan Provinsi Kalimantan Timur Tahun 2016, menunjukkan tanaman lada di Kutai Kartanegara mengalami penyakit busuk pangkal batang yang merupakan $10 \%$ dari 67 ha luas lahan tanaman lada yang mengakibatkan kerugian bagi para petani. Berdasarkan survei awal peneliti ditemukan bertambahnya jumlah tanaman lada yang bergejala penyakit busuk pangkal batang di Kecamatan Loa Janan, Desa Batuah. Dari informasi tersebut perlu dilakukan penelitian intensitas penyakit busuk pangkal batang pada beberapa kelompok tani lada di Desa Batuah dan mengisolasi dan identifikasi penyebab penyakit tersebut.

\section{BAHAN DAN METODE}

Bahan yang digunakan dalam penelitian ini adalah tanaman lada petani di Desa Batuah, bagian tanaman yang terserang penyakit, media potato dextros agar (PDA) untuk mengisolasi jamur penyebap penyakit busuk pangkal batang di Laboratorium Ilmu Hama Dan Penyakit Tumbuhan, Fakultas Pertanian Universitas Mulawarman Samarinda. Penelitian ini menggunakan metode survei langsung ke lahan petani lada dan diskriptif.

\section{A. Prosedur Kerja}

Pengambilan data. Pada penelitian ini diperlukan data sekunder dan data Primer. Data sekunder berasal dari Dinas Perkebunan Kalimantan Timur untuk mempersiapkan survei di lapangan, meliputi pengumpulan data - data tentang lahan - lahan yang akan diambil sampel, pengecekan dan persiapan bahan - bahan yang akan digunakan. Selain itu juga data monografi desa didapatkan dari Kecamatan Loa Janan, untuk mengetahui kondisi lahan. Lahan pengambilan sampel dalam penelitian ini adalah lokasi yang merupakan sentra perkebunan tanaman lada. Lokasi yang di jadikan untuk pengambilan sampel adalah Kecamatan Loa Janan, Desa Batuah pada Kelompok Tani Lada Muda, Mega Buana, Mario, Berkah Mandiri, Masa Kini, Tani Baru, Tunas Mekar, dan Beringin Jaya. Data primer didapatkan dari hasil survei dan penghitungan tanaman yang sehat dan yang bergejala penyakit busuk pangkal batang lada di delapan kelompok tani tersebut. Pengambilan sampel tanaman yang bergejala penyakit dilakukan di delapan kelompok tani, kemudian dibawa ke laboratorium untuk diisolasi, diindentifikasi. Data yang diperlukan untuk identifikasi jamur patogen adalah warna koloni, jenis hifa (bersekat atau tidak), bentuk hifa, bentuk spora kemudian membandingkan dengan buku identifikasi jamur (Alexopoulus and Mims. 1979). Setelah teridentifikasi lanjutkan dengan langkahlangkah dalam postulat Koch..

Analisis data. Data gejala penyakit busuk batang lada dari hasil pengamatan di lapangan dianalisa secara deskriktif. Penyakit busuk pangkal batang lada bersifat sitemik, dimana serangan patogen cepat atau lambat akan menyebabkan kematian sehingga tidak dapat melanjutkan produksinya. Pengukuran intensitas penyakit tanaman dengan menggunakan rumus kejadian penyakit (disease incidance), dihitung menggunakan rumus sebagai berikut (Khaeruni dkk, 2016) :

$$
\mathrm{IP}=\mathrm{n} / \mathrm{N} \times 100 \%
$$

Keterangan :

IP = Intensitas Penyakit

$\mathrm{n}=$ Jumlah tanaman yang bergejala

$\mathrm{N}=$ Jumlah tanaman yang diamati

Tabel 1. Kriteria serangan berdasarkan kejadian penyakit

\begin{tabular}{ll}
\hline $\begin{array}{l}\text { Tingkat kejadian } \\
\text { penyakit (\%) }\end{array}$ & Kriteria \\
\hline 0 & Normal \\
$1 \leq \mathrm{x} \leq 25$ & Ringan \\
$25<\mathrm{x} \leq 50$ & Sedang \\
$50<\mathrm{x} \leq 75$ & Berat \\
$\mathrm{x}>75$ & Sangat Berat \\
\hline
\end{tabular}

Sumber : Natawigena (1982) 
Lokasi penelitian di Desa Batuah, Kecamatan Loa Janan, Kabupaten Kutai Kartanegara, secara geografis terletak pada posisi antara $116^{\circ} 49^{\prime} \mathrm{BT}$ $117^{\circ} 08^{\prime}$ BT dan $0^{\circ} 34^{\prime}$ LS - $0^{\circ} 45^{\prime}$ LS (Kutai Kartanegara dalam angka, 2016). Desa Batuah memiliki luas wilayah $84 \mathrm{~km}^{2}$, dilintasi oleh jalan poros Balikpapan-Samarinda. Jumlah penduduk 8.853 jiwa, dimana mayoritas mata pencaharian penduduknya adalah petani lada. Luas lahan perkebunan lada di delapan kelompok mencapai 202 ha.

Table 2. Pengendalian Penyakit dan Pemupukan Tanaman Lada di Desa Batuah

\begin{tabular}{|c|c|c|c|}
\hline No. & Kelompok Tani & Pengendalian Penyakit & Pemupukan/tahun \\
\hline 1 & Lada Muda & $\begin{array}{l}\text { Kultur teknis } \\
\text { Pengandalian hayati } \\
\text { Kimia }\end{array}$ & $\begin{array}{l}\text { Kimia (2 kali) } \\
\text { Organik(1 kali) }\end{array}$ \\
\hline 2 & Mega Buana & $\begin{array}{l}\text { Kimia } \\
\text { Kultur teknis } \\
\text { Pengendalian mekanis }\end{array}$ & $\begin{array}{c}\text { Kimia (1 kali) } \\
\text { Organik (2 kali) }\end{array}$ \\
\hline 3 & Mario & $\begin{array}{l}\text { Kimia } \\
\text { Pengandalian hayati } \\
\text { Pengendalian mekanis }\end{array}$ & $\begin{array}{c}\text { Kimia (1 kali) } \\
\text { Organik (3 kali) }\end{array}$ \\
\hline 4 & Berkah Mandiri & $\begin{array}{l}\text { Kimia } \\
\text { Kultur teknis } \\
\text { Pengendalian mekanis }\end{array}$ & $\begin{array}{c}\text { Kimia (1 kali) } \\
\text { Organik (2 kali) }\end{array}$ \\
\hline 5 & Masa Kini & $\begin{array}{l}\text { Kimia } \\
\text { Pengendalian hayati } \\
\text { Kultur teknis } \\
\text { Pengendalian mekanis }\end{array}$ & $\begin{array}{c}\text { Kimia (1 kali) } \\
\text { Organik (2 kali) }\end{array}$ \\
\hline 6 & Tani Baru & $\begin{array}{l}\text { Kultur teknis } \\
\text { Pengendalian mekanis }\end{array}$ & $\begin{array}{c}\text { Kimia (1 kali) } \\
\text { Organik (1 kali) }\end{array}$ \\
\hline 7 & Tunas Mekar & $\begin{array}{l}\text { Kimia } \\
\text { Kultur teknis } \\
\text { Pengendalian mekanis }\end{array}$ & $\begin{array}{l}\text { Kimia (1 kali) } \\
\text { Organik (2 kali) }\end{array}$ \\
\hline 8 & Beringin Jaya & $\begin{array}{l}\text { Pengandalian hayati } \\
\text { Kultur teknis } \\
\text { Pengendalian mekanis }\end{array}$ & $\begin{array}{l}\text { Kimia (1 kali) } \\
\text { Organik (2 kali) }\end{array}$ \\
\hline
\end{tabular}

Gejala khas tanaman lada yang terserang penyakit busuk pangkal batang adalah layunya tanaman. Daun menjadi kuning dan lemas. Kemudian menghitam mulai dari ujungnya, setelah itu daun gugur. Gugurnya daun mulai dari cabangcabang yang paling bawah dan menjalar ke atas.
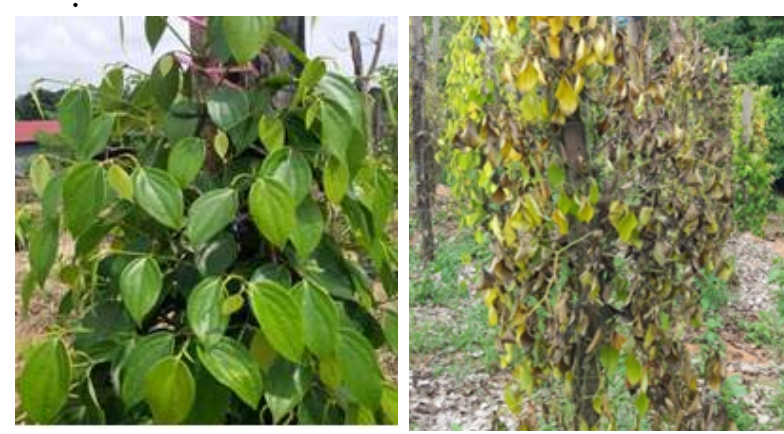

Gambar 1. a). Tanaman Lada yang Sehat

b). Tanaman Lada yang Bergejala Penyakit Busuk Pangkal Batang

Patogen busuk pangkal batang lada dapat menyerang semua umur tanaman, mulai dari
Setelah tampaknya gejala layu yang pertama kali, biasanya penyakit berkembang dengan lebih cepat, sehingga tanaman mati dalam waktu 10 hari, bahkan dalam cuaca kering tanaman mati dalam waktu 3-4 hari. Tanaman lada yang sehat dan yang bergejala penyakit dapat dilihat pada Gambar 1

pembibitan sampai tanaman produktif. Serangan yang paling membahayakan adalah pada pangkal batang atau akar karena menyebabkan kematian tanaman dengan cepat. Gejala berupa kelayuan tanaman secara mendadak (daun tetap berwarna hijau akan nampak apabila terjadi serangan patogen pada pangkal batang. Pangkal batang yang terserang menjadi berwarna hitam, pada keadaan lembab akan nampak lendir yang berwarna kebiruan. Serangan pada akar, menyebabkan tanaman layu dan daun-daun menjadi berwarna kuning (Mulya dkk., 2003). Serangan pada daun menyebabkan gejala bercak daun pada bagian tengah, atau tepi daun. Bercak berwarna hitam dengan tepi bergerigi seperti renda yang akan 
nampak jelas apabila daun diarahkan ke cahaya. Gejala khas tersebut hanya nampak pada bercak yang belum lanjut dan terjadi pada keadaan lembap . Pengamatan lebih lanjut pada lapisan air yang ada di permukaan bawah bercak daun, tampak adanya sporangia patogen. Biasanya daun-daun yang terinfeksi ini merupakan sumber inokulum bagi tangkai atau cabang yang berada di dekatnya. Apabila selama waktu hujan disertai terjadinya angin, maka propagul patogen dapat terbawa dan menyebar ke daun tanaman di sekitarnya. Serangan pada buah menyebabkan buah berwarna hitam, dan busuk, gejala ini biasanya banyak ditemukan pada buah yang letaknya dekat permukaan tanah (Manohara dkk., 19006).

Pengamatan di Desa batuah berbeda jarak tanamnya tanaman lada, sehingga di setiap kelompok tani juga berbeda populasinya. Intensitas penyakit busuk pangkal batang tanaman lada berkisar antara $4,3 \%-26,52 \%$ atau dari kriteria ringan sampai sedang. Rata-rata kejadian penyakit $14,58 \%$ atau masih dalam kriteria ringan, lebih rinci dapat dilihat pada Tabel 3.

Table 3. Intensitas Penyakit Busuk Pangkal Batang dan Produksi Tanaman Lada di Desa Batuah, Kec. Loa

\begin{tabular}{cccccc} 
Janan, Kab.Kutai Kartanegara & & & \\
\hline No. & Kelompok Tani & $\begin{array}{c}\text { Luas Lahan } \\
\text { (ha) }\end{array}$ & $\begin{array}{c}\text { Intensitas } \\
\text { penyakit (\%) }\end{array}$ & Kriteria & $\begin{array}{c}\text { Produksi } \\
\text { (Mg) }\end{array}$ \\
\hline 1 & Lada Muda & 46 & 26,52 & Sedang & 46 \\
2 & Mega Buana & 29 & 6,17 & Ringan & 33 \\
3 & Mario & 20 & 6,13 & Ringan & 20 \\
4 & Berkah Mandiri & 20 & 18,00 & Ringan & 10 \\
5 & Masa Kini & 30 & 25,00 & Ringan & 30 \\
6 & Tani Baru & 12 & 13,00 & Ringan & 7,5 \\
7 & Tunas Mekar & 20 & 17,50 & Ringan & 20 \\
8 & Beringin Jaya & 25 & 4,30 & Ringan & 12 \\
\hline
\end{tabular}

Hasil isolasi patogen busuk pangkal batang, terlihat bahwa koloni jamur pada hari ketiga dan keempat berwarna putih (Gambar 2a), pada hari kelima warna koloni berubah menjadi coklat dan seterusnya berwarna kehitaman. Hasil pengamatan secara mikroskopis terlihat sporangium jamur Phytophthora capsici L insitu (Gambar 2b). Pola koloni isolat Phytophthora capsici L. yang diamati sangat bervariasi, mulai dari halus tidak berpola hingga yang tebal dan membentuk pola seperti bunga. Semua isolat mempunyai papilla yang jelas pada ujung sporangium. Bentuk sporangium juga sangat bervariasi, mulai dari yang berbentuk bulat hingga berbentuk seperti buah pir atau lemon dan merupakan bentuk sporangium yang paling banyak ditemukan pada Phytophthora tanaman lada. Hasil langkah-langkah dalam postulat Koch, diketahui jamur patogen ini terbukti penyebab penyakit busuk pangkal batang tanaman lada.

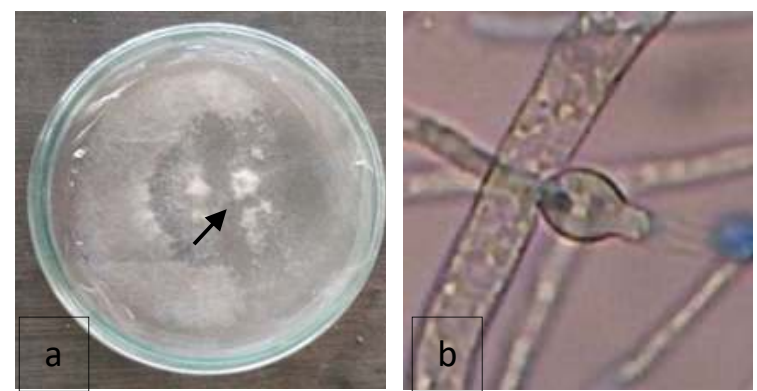

Gambar 2. a) Koloni jamur Phythophtora sp.

b)Sporangium Phytophthora capsici Leonian (400x) insitu

Data pada Tabel 3 terlihat bahwa kejadian penyakit busuk pangkal batang perlu diwaspadai, karena intensitas sudah mencapai kriteria sedang. Penyakit ini sangat ditakuti petani karena dapat menyebar dengan cepat dan mematikan tanaman dalam waktu singkat (Manohara dkk., 2005). Pemupukan organik dan pengendalian menggunakan agent hayati perlu ditingkatkan untuk menghambat penyebaran patogen busuk pangkal batang lada. Pengendalian penyakit yang 
dilakukan di lapangan diantaranya, pengandalian hayati menggunakan Trichoderma. Trichoderma harzianum, merupakan musuh alami dari Phytophthora capsici. Hasil penelitian menunjukkan bahwa dengan aplikasi jamur Trichoderma harzianum dapat menekan intensitas serangan penyakit busuk pangkal batang sekitar 50\% (Manohara dkk, 2003; Wahyuno dkk., 2003). Pengendalian kultur teknis dengan pembuatan drainase/parit di sekitar tananaman, sehingga tidak ada air yang tergenang di dalam kebun. Adanya air yang tergenang merupakan tempat atau kondisi yang baik untuk pertumbuhan dan perkemangan jamur Phytophthora capsici L. Selanjutnya, pengendalian mekanis yaitu dengan mencabut tanaman yang terkena penyakit lalu dibakar.

Faktor lain yang mempengaruhi penyebaran Phytophthora capsici L. adalah saat musim hujan, suhu udara menjadi rendah dan kelembaban tinggi serta didukung oleh adanya nutrisi yang cukup akan merangsang struktur istirahat jamur patogen tersebut untuk berkecambah. Tetesan air hujan yang jatuh ke tanah dapat membantu memindahkan propagul dari tanah ke daun yang di dekatnya sehingga memungkinkan terjadinya infeksi. Menurut Manohara dan Machmud (1986), infeksi pada daun terjadi 4 - 6 jam setelah diinokulasi dengan zoospora dan menimbulkan gejala berupa titik hitam setelah $18-20$ jam diinokulasi. Kebun lada yang disiang bersih akan mengalami kerusakan lebih parah $(50-80 \%$ diserang busuk pangkal batang dibandingkan kebun yang disiang terbatas (Manohara dkk, 1993). Pertanaman lada yang gulmanya banyak mempunyai laju infeksi yang lebih rendah dibandingkan dengan pertanaman lada yang gulmanya sedikit.

Penyebaran jamur Phytophthora capsici L. selain oleh air dan angin yang terjadi selama hujan, juga dapat terbawa oleh ternak peliharaan, siput/keong, manusia, alat pertanian bekas dipakai pada tanaman sakit, bahkan dapat terbawa oleh bibit lada sehingga menjadi sumber inokulum bagi daerah pengembangan lada yang baru (Mulya dkk., 2003). Distribusi bibit yang telah terinfeksi patogen, merupakan sarana penyebaran penyakit yang potensial (Zapata-Vazquez dkk, 2012). Jenis tanah tidak mempengaruhi model perkembangan penyakit busuk pangkal batang lada tetapi mempengaruhi laju infeksi penyakit. Laju infeksi penyakit busuk pangkal batang lada lebih rendah pada jenis tanah Ultisol dibanding pada tanah Entisol.

Apabila dilihat produksinya (Tabel 3) maka intensitas penyakit busuk pangkal batang lada tidak begitu berpengaruh terhadap produktifitas baik yang kategori ringan maupun yang sedang, yaitu \pm $1 \mathrm{Mgha}^{-1}$ setiap kali panen pada lahan. Petani melakukan pemupukan menggunakan pupuk organik (pupuk kandang) yang diberikan rata-rata 2 kali dalam satu tahun. Pemberian pupuk kimia yaitu Urea, KCL dan NPK, diberikan rata-rata 1 kali dalam satu tahun. Pemupukan dilakukan pada setiap musim awal penghujan dan musim akhir musim panas diberikan masing-masing dari dosis yang ditentukan. Pemupukan pada tanaman lada selain menambah unsur hara juga berpengaruh positif terhadap ketahanan tanaman terhadap penyakit dan cekaman air akibat kekeringan. Pupuk organik berupa pupuk kandang atau kompos sebanyak 5-10 $\mathrm{kg} /$ tanaman/tahun. Pemberian pupuk dilakukan dengan mengangkat permukaan tanah di sekitar tanaman, pupuk disebarkan kemudian ditutup kembali dengan tanah kikisan ditambah tanah dari sekitar tanaman

Menurut penelitian Zaubin dkk., (1991) bahwa komposisi hara NPK tertentu berpengaruh terhadap ketahanan tanaman lada terhadap serangan penyakit busuk pangkal batang. Usaha meningkatkan produktivitas lada, kendala kesuburan tanah dan serangan penyakit dapat di Kalimantan Barat ditanggulangi melalui pemupukan. Murni dan Zaubin dalam Asnawi dkk., (2017) melaporkan bahwa pemupukan pada tanaman lada di Lampung dengan dosis $1200 \mathrm{~g}$ NPKMg (12-12-17-2) setara dengan 313,04 g Urea, 400 g SP-36, $408 \mathrm{~g} \mathrm{KCl}, 60 \mathrm{~g}$ dolomit ternyata memberikan hasil tertinggi, dosis pupuk lebih tinggi tidak meningkatkan hasil yang nyata.

\section{KESIMPULAN}

Berdasarkan hasil penelitian yang telah dilakukan, maka dapat disimpulkan bahwa di desa batuah Kecamatan Loa Janan Kabupaten Kutai Kartanegara umumnya menanam varietas Malonan-1. Rata-rata intensitas penyakit busuk pangkal batang tanaman lada (Piper nigrum L) mencapai 14,58\%, dengan kriteria intesitas serangan penyakit tergolong ringan. Penyebab penyakit busuk pangkal batang tanaman Lada di Desa Batuah adalah Phytophthora capsici L. Intensitas penyakit busuk pangkal batang lada tidak mempengaruhi produktivitas lada.

\section{DAFTAR PUSTAKA}


Alexopoulus, C.J and C.W Mims. 1979. Introductory Mycology. John Wiley and Sons. New York.

Asmawi, R. Zahara dan Arief, R.W, 2017. Pengaruh Pengolahan Faktor Internal Usaha Tani Terhadap Produktivitas Lada di Provensi Lampung. Jurnal Litri. Balai Pengkajian Teknologi Pertanian Lampung. Vol. 23. Hal 1-10 ISSN: 053-8212.

Kementan. 2017. Produksi dan Ekspor Lada meningkat, Kementan Optimis Rempah Kembali Berjaya. Kementerian Pertanian Republik Indonesia. Jakarta. http://bit.ly/ekslada. Diakses 4 juli 2019

Khaeruni. A. Asniah. Taufik, M. Sutariati, G. A. K. 2014. Aplikasi Formula Campuran Rizobakteri Untuk Pengandalian Busuk Akar Rhyzoctona dari Peningkatan Hasil Kedelai. Jurnal Fitologi Indonesia. Universitas Halu Oleo, Kendari. Vol:10 Hal 37-44. ISSN: 2339-2979.

Manohara, D. dan M. Machmud, 1986. Proses infeksi Phytophthora palmivora (Butl.) pada daun lada (Piper nigrum L.). Pembr. LPTI. 11:60-66.

Manohara, D., D. Wahyuno dan R. Noveriza. 2005. Penyakit busuk pangkal batang Lada dan strategi pengendaliannya. Perkembangan Teknologi Tanaman Rempah dan Obat. 17:41-51.

Manohara, D., D. Wahyuno, dan Sutrasman. 1993. Kajian tiga isolat Phytophthora capsici asal lada, cabe Jawa, dan sirih. Kongres XII dan Seminar Ilmiah Perhimpunan Fitopatologi Indonesia. Yogyakarta, 6-8 September 1993. hlm. 942-947.

Manohara, D., P. Wahid, D. Wahyuno, Y. Nuryani, I. Mustika, I.W. Laba, Yuhono, A.M. Rivai dan Saefudin. 2006. Status teknologi tanaman Lada. Prosiding Status Teknologi Tanaman Rempah dan Aneka Tanaman Industri, Parungkuda-Sukabumi, 26 September 2006. $1-57 \mathrm{pp}$.

Mulya, K., Wahyuno, D. dan Noveriza, R., 2003. Viabilitas Trichoderma harzianum pada berbagai formula dan efikasinya terhadap Phytophthora capsici. Risalah Simposium Nasional Penelitian PHT Perkebunan Rakyat. Bogor, 17-18 Mei 2019.

Pemkab Kukar 2016. Kecamatan Loa Janan. Pemerintah Kabupaten Kutai Kartanegara. Kutai Kartanegara. http://kabupaten.kutaikartanegara.com/kecam atan.php?k=Loa_Janan. Diakses 4 Juli 2019
Semangun, H. 2000. Penyakit-penyakit Tanaman Perkebunan di Indonesia. Gadjah Mada University Press, Yogyakarta.

Wahyuno, D., D. Manohara, K. Mulya. 2007. Penyebaran dan usaha pengendalian penyakit busuk pangkal batang Lada di Bangka. Prosiding Seminar Nasional Rempah. Bogor.

Wahyuno D, Manohara D. 1995. Pembentukan spora Phytophthora capsici pada jaringan Lada.Jurnal Hayati vol 2(1): 46-48. Diakses tanggal 20 Agustus 2018.

Zapata-Vázquez A, Sánchez-Sánchez M, del-RíoRobledo A, Silos-Espino H, Perales-Segovia C, Flores-Benítez S, González-Chavira M, Valera-Montero LL. 2012. Phytophthora capsici epidemic dispersion on commercial pepper fields in Aguascalientes, Mexico. The Scientific World J. 2012:1-5. DOI: https://doi. org/10.1100/2012/341764.

Zaubin. R. H. dan T. Sunarti. 1991. Pengaruh Dosis dan Komposisi NPK terhadap Serangan Penyakit BPB Lada. Seminar Sub Balittro Natar. 11p. 